\title{
Polylactic Acid/Empty Fruit Bunch Fiber Biocomposite: Influence of Alkaline and Silane Treatment on the Mechanical Properties
}

\author{
Rosman Senawi, Sakinah Mohd Alauddin, Ruzitah Mohd Saleh, and Mohammed Iqbal Shueb
}

\begin{abstract}
Biocomposite were prepared by combining polylactic acid (PLA)with treated or untreated empty fruit bunch (EFB) fiber by melt compounding method to observe the effects of fiber surface treatments on the mechanical properties of the biocomposite. Surface treatment of the fiber was conducted using alkali followed by silane treatment. It was found that treated fibers showed superior mechanical properties of the reinforced biocomposite as compared with untreated fiber reinforced biocomposites due to the enhanced adhesion between the EFB fiber and the PLA matrix.
\end{abstract}

Index Terms-Biocomposites, empty fruit bunch, polylactic acid, surface treatments

\section{INTRODUCTION}

Composites have lately received much attention in research, developmental sector as well as industry due to the high demand in applications such as construction, automotive to aerospace industries [1]. Composites used are usually composed of synthetic polymer as the matrix and synthetic fiber such as glass, aramid or carbon fiber as the reinforcement. However, both matrix and reinforcement are the source of rising environmental problems since they do not degrade in landfills or composting environments[2]. Thus, biocomposites have been developed as an alternative to these composites as they offer environmental advantages at the end of their cycle due to their biodegradability [3].

Polylactic acid (PLA) a corn based polymer has recently been introduced commercially for products where biodegradability is required [4]. Currently, PLA is the major thermoplastic polymer made from renewable resources which is produced in large scales with a capacity of 140000 tons per year [5]. PLA provides good aesthetics, strength and easy processability in most equipment and is thus used in various areas of applications such as fiber/textile, food packaging, film and interior automotive parts [6]. However, PLA has its drawback such as brittleness and fast degradation above its glass transition temperature [7], [8] and thus needs modification for enhanced performance.

Reinforcement can be achieved byusing natural fibersin order to improve mechanical and thermal properties of PLA [9]. Natural fibers have reinforcing efficiency which is

Manuscript received October 9, 2012; revised November 27, 2012. This work was supported in part by Chemical Engineering, Universiti Teknologi MARA (UiTM)

Rosman Senawi, Sakinah Mohd Alauddin, and RuzitahMohdSaleh are with the Universiti Teknologi MARA (UiTM) (e-mail: rosman1979@gmail.com)

Mohammed Iqbal Shueb is with Malaysian Nuclear Agency. related to the nature of their cellulose andcrystallinity. They are also biodegradable, renewable, harmless to humans, less abrasive to processing equipments and have comparable mechanical properties with inorganic fibers [10]. A potential natural fiber which has been the subject of studies by many researchersis empty fruit bunch (EFB). EFB is a tough fiberproduced as a by-product of palm oil extraction [11].

Interfacial adhesion between matrix and fiber is usually an obstacle due to their different polaritieswhich results indiminished composite properties. However, this can be improved by using chemical modification of the fiber, either by chemical solution [7] or free radical reaction [12], use of modified thermoplastic containing a compound capable of interacting with the fiber [13], or addition of a third component (a compatibiliser) with the ability to interact simultaneously at the interface with the thermoplastic and the fiber [14], [15].

In this paper, two surface treatments methods have been used; EFB fiber treated with alkaline solution followed bysilane coupling agent. The main aim of this research is to investigate the influence of alkaline and silane treatments to the mechanical properties of EFB/PLA biocomposites.

\section{EXPERIMENTAL}

\section{A. Fiber Surface Treatment}

EFB fibers were collected from Sime Darby Plantation in Labu, Negeri Sembilan and were dried for three days before grinding to obtain a uniform size of $400 \mu \mathrm{m}$. The fibers were then soaked in hot distilled water at $70^{\circ} \mathrm{C}$ for 4 to 6 hours to remove impurities and large particles [7]. Next, the fibers were dried in an air oven at $105^{\circ} \mathrm{C}$ for 12 hours to remove the moisture [8]. These dried fibers are designated as untreated fibers.

The untreated EFB fibers were initially treated with alkaline solution is to obtain cleaner and rougher fiber surface which provides both mechanical interlocking and the bonding reaction due to exposure of the hydroxyl groups to the matrix [16]. Treatment was conducted by soaking the fibersin $(5 \%$ w/v) sodium hydroxide $(\mathrm{NaOH})$, obtained from Bendosen Laboratory Chemicals, solution for 2 hours at room temperature before washed with distilled water containing a few drops of acetic acid and followed by distilled water until all $\mathrm{NaOH}$ was removed by checking the $\mathrm{pH}$. After washing, the fibers were left to dry for 2 days at room temperature. The fibers were then dried in air for 6

hours followed by drying in an oven at $80^{\circ} \mathrm{C}$ for another 6 hours. Subsequently, the fibers weresilane treated to improve the degree of cross-linking between the matrix and 
the fiber.This was done by dissolving the alkaline treated fibers in $5 \mathrm{wt} \%$ 3-Aminopropyltriethoxysilane (APS), purchased from Sigma-Aldrich, (weight percentage compared to fiber) for hydrolysis in a mixture of waterethanol $(40: 60 \mathrm{w} / \mathrm{w})$. The $\mathrm{pH}$ of the solution was adjusted to 4 by adding acetic acid and stirred continuously for 1 hour. The fibers were then soaked in the solution for 3 hours. Next, the fibers were washed and left to dry for 3 days. Finally, the fibers were oven dried at $80^{\circ} \mathrm{C}$ for 12 hours.

TABLE I: MEChANiCAL PRoPerties of TREATED AND UNTREATEd Fiber BIOCOMPOSITE

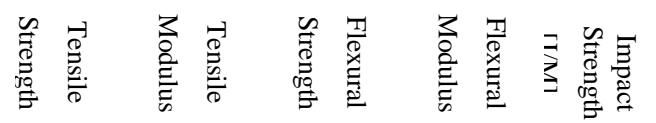

\begin{tabular}{lccccc} 
Untreated & 30.2 & 0.9 & 72.1 & 3.1 & 31.4 \\
fiberbiocompostie & & & & & \\
$\begin{array}{l}\text { Treated } \\
\text { fiberbiocomposite }\end{array}$ & 53.0 & 1.1 & 84.4 & 4.4 & 35.0 \\
\hline
\end{tabular}

\section{B. Preparation of Biocomposites}

PLA, purchased from NatureWorks LLC, was used as the base resin in this biocomposite compound. The melting temperature for this PLA is $150^{\circ} \mathrm{C}$ to $170^{\circ} \mathrm{C}$ to prevent EFB fibers degradation during processing. Prior mixing, PLA resins was dried for 2 hours at $90^{\circ} \mathrm{C}$ while $\mathrm{EFB}$ fibers were predried for 12 hours in a hot air oven at $105^{\circ} \mathrm{C}$ to remove moisture content. The PLA/EFB biocomposites were then prepared using an internal mixer type HaakeRheomixer at $160^{\circ} \mathrm{C}$ with a rotor speed of $50 \mathrm{rpm}$. The amount of fiber used was $10 \mathrm{wt} \%$. The biocomposites was then compression moulded using a hot press at $180^{\circ} \mathrm{C}$ with $150 \mathrm{~kg} / \mathrm{m}^{2}$ pressure. Molded sheets than were cut using to obtain specimen for tensile, flexural and impact testing.

\section{Testing}

An INSTRON Universal Testing Machine (Model 4301) was used to measure tensile and flexural properties according to ASTM D 638 and ASTM D 790 respectively. The morphology of the fiber surface was observed using a Quanta FEG, 450Scanning Electron Microscope (SEM) with an accelerating voltage of $10 \mathrm{kV}$ at room temperature. The specimens were vacuum coated with a thin layer of platinum using JEOL JFC-1600.

\section{RESULTS AND DISCUSSION}

\section{A. Tensile test}

Mechanical properties of composites depend on the adhesion between the matrix and the fiber. Generally, fiber surface modification improvesbiocompositesproperties by decreasing the moisture absorption, increasing wettability and interfacial bond strength with the matrix [16].

The superior tensile strengthof the treated biocompositeshowed in Table $\mathrm{I}$ is due to the treatment method applied. Alkali treatment removes surface impurities and makes fiber surface rougher [7]. This is proved by SEM picture Fig. 1(b) which shows a rougher fiber surface after $\mathrm{NaOH}$ treatment. This is different with Fig. 1(a) where the fiber surface is clean. The rough surfaces increase the additional sites of mechanical interlocking and promote more matrix or fiber interpenetration at the surface [17].

Silane treatmentenhances compatibility by linking the fiber surfaces and matrix with its silanol and amino functional groups. The silanol group will react with fiber hydroxyl groups through an ether linkage with removal of water as shown in equation 1 [18]. Whereas, the other functional group of silane, amino group, will react with the hydroxyl groups of the PLA forming a chemical bonding linkage between the matrix and the EFB fiber. It can be concluded, surface modification improve the tensile strength of the biocomposites.

$$
\begin{aligned}
& \mathrm{NH}_{2}\left(\mathrm{CH}_{2}\right)_{3} \mathrm{Si}\left(\mathrm{OC}_{2} \mathrm{H}_{5}\right)_{3}+\mathrm{H}_{2} \mathrm{O}+\text { Fiber } \mathrm{OH} \\
& \mathrm{NH}_{2}\left(\mathrm{CH}_{2}\right)_{3} \mathrm{Si}(\mathrm{OH})_{2} \quad \mathrm{O} \quad \text { Fiber }+2 \mathrm{H}_{2} \mathrm{O}
\end{aligned}
$$

Equation 1: Reaction of silanol with fiber hydroxyl group

The increased in tensile modulus after treatment can be described by uniform dispersion of fibers in the PLA matrix lead to even distribution and transfer of stress from matrix to fiber [19].Similar results were observed by Rosa et al. [20] and John et al. [17] who reported that alkali and silane treatment resulted in higher value of tensile properties compared with untreated fiber.

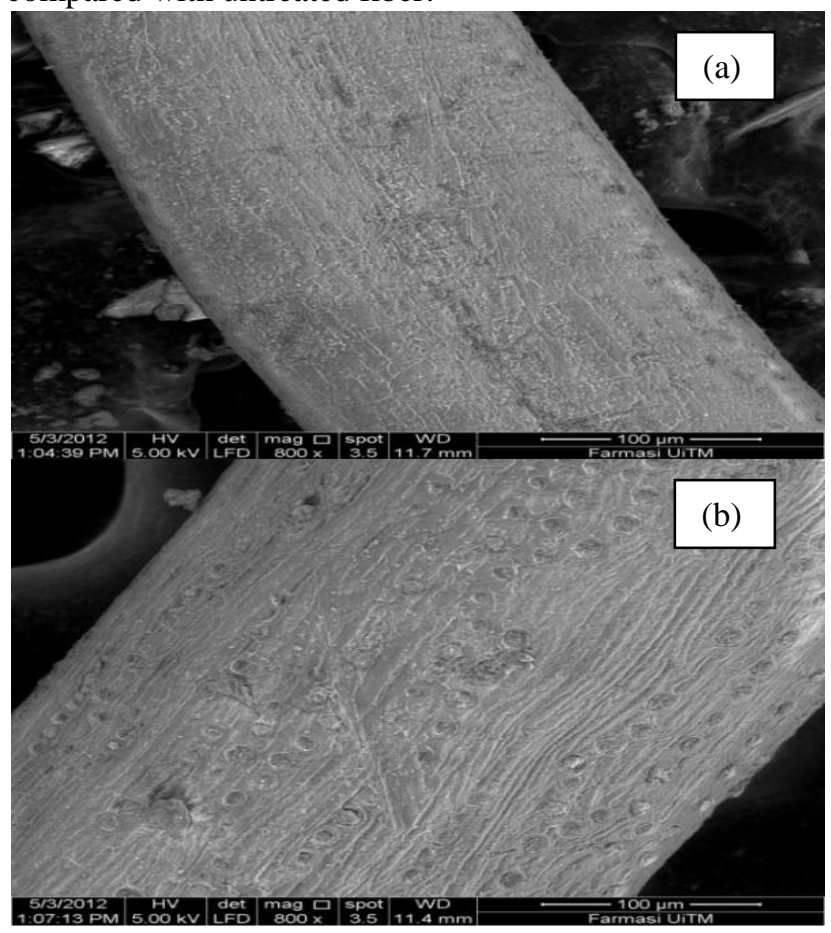

Fig. 1. SEM images of EFB fiber: (a) Untreated fiber; (b) alkali treated

\section{B. Flexural Test}

Fiber treated with alkali and silane showed a $17 \%$ increase in flexural strength value compared with untreated fiberbiocomposite. When EFB fiber treated with alkali, the fiber becomes cleaner and rougher surface. During compounding, it facilitates both mechanical interlocking and the bonding reaction due to the exposure of the hydroxyl groups [21]. 
The treated biocomposites exhibited a superior increase in flexural modulus of $42 \%$. There are many factors affecting the modulus of the biocomposites such as filler loading, modulus and aspect ratio [18]. The increasing in flexural modulus value after treatment suggests an efficient stress transfer between between the fiber and the matrix after treatment the fiber. Another reason is good dispersion or mixing between the fiber and the matrix [9].

The notch Izod impact strength test measures the energy required for the propagation of the existing crack [22]. Impact strength of the fiber reinforced polymer composites are dependent on the fiber/matrix adhesion, toughness of the matrix and the fiber, crystalline morphology, defects in the packing of fiber/matrix, etc. [23]. Based on table 1, alkali followed by silane treatment improved the impact values of the biocomposites by $11 \%$. This enhance value is due to the improvement of the interfacial adhesion between the fiber and the matrix. During Izod impact test, the improved interfacial adhesion provides higher resistance to crack propagation [7].

\section{CONCLUSIONS}

In this work, biocomposites were produced from treated and untreated EFB fibers. Treated EFB fibers were surface treated with alkali and silane to increase their compatibility with the PLA matrix. Mechanical tests conducted showed improved values compared with untreated fibers. Alkali treatment is effective in removing impurities producing a rougher fiber surface which promote fiber adhesion as proven by SEM images. Silane treatment acts as bridge between the PLA matrix and the fiber. According to the results, combination alkali and silane is the best surface treatment to obtain optimum results. Further study will be focused on thermal properties of the biocomposite.

\section{ACKNOWLEDGEMENTS}

Authors are grateful for the financial support provided byMinistry of Higher Education for the Fundamental Research Grant Scheme (FRGS) and UniversitiTeknologiMARA (UiTM), Shah Alam that has made this research work possible. Thanks to the staff of Pharmacy Faculty, UiTM Shah Alam for SEM measurements and Malaysia Nuclear Agency for their technical support in carrying out this research.

\section{REFERENCES}

[1] B.-H. Lee, H.-S. Kim, S. Lee, H.-J. Kim, and J. R. Dorgan, "Biocomposites of Kenaf Fibers in Polylactide: Role of Improved Interfacial Adhesion in the Carding Process," Composites Science and Technology, 2009.

[2] M. S. Huda, L. T. Drzal, A. K. Mohanty, and M. Misra, "Effect of fiber surface treatments on the properties of laminated biocomposites from poly(lactic acid) (PLA) and kenaf fibers," Composites Science and Technology, vol. 68, pp. 424-432, 2008.

[3] T. Ohkita and S. H. Lee, "Thermal degradation and biodegradability of poly (lactic acid)/corn starch biocomposites," J. ApplPolym Sci., vol. 100, pp. 3009-3017, 2006.
[4] K. Oksman, M. Skrifvars, and J. F. Selin, "Natural fibres as reinforcement in polylactic acid (PLA) composites," Composites Science Technology, vol. 63, pp. 1324-1327, 2003.

[5] B. Bax and J. Mussig, "Impact and tensile properties of PLA/Cordenka and PLA/flax composites," Composites Science and Technology, vol. 68, pp. 1601-1607, 2008.

[6] A. M. Harris and E. C. Lee, "Injection Molded Polylactide (PLA) Composites for Automotive Applications," SPE ACCE Paper Draft 062906, 2006.

[7] T. Yu, J. Ren, S. Li, H. Yuan, and Yan Li, "Effect of fiber surfacetreatments on the properties of poly(lactic acid)/ramie composites," Composites Part A, vol. 41, pp. 499-505, 2010.

[8] M. S. Huda, A. K. Mohanty, L. T. Drzal, and M. Misra, "Physicomechanical Properties of 'Green' Composites from Polylactic Acid (PLA) and Cellulose Fibers," GPEC Paper Abstract, 2004.

[9] M. S. Huda, L. T. Drzal, and M. Misra, "A study on biocomposites from recycled newspaper fiber and poly(lactic acid) (PLA) and kenaf fibers," IndEngChem Res., vol. 44, pp. 5593-5601, 2005.

[10] S. S. Suradi, R. M. Yunus, M. D. H. Beg, M. Rivai, and Z. A. M. Yusof, "Oil Palm Bio-Fiber Reinforced Thermoplastic CompositesEffects of Matrix Modification on Mechanical and Thermal Properties," Journal of Applied Science, vol. 10, pp. 3271-3276, 2010.

[11] Md. M. Haque, M. Hasan, Md. S. Islam, and Md. E. Ali, "Physicomechanical properties of chemically treated palm and coir fiber reinforced polypropylene composites," Bioresource Technology, vol. 100, pp. 4903-4906, 2009.

[12] A. K. Bledzki, A. A. Mamun, M. L. Gabor, and V. S. Gutowski, "The effects of acetylation on properties of flax fibre and its polypropylene composites," Express Polymer Letters, vol. 2, pp. 413-422, 2008.

[13] K. L. Fung, R. K. Y. Li, and S. C. Tjong, "Interface modification on the properties of sisal fibre reinforced polypropylene composites," Journal of Applied Polymer Science, vol. 85, pp. 169-176, 2002.

[14] D. Feng, D. F. Caulfiel, and A. R. Sanadi, "Effect of compatibiliser on the structure-property relationships of kenaffibre/polypropylenecomposites," Polymer Composite, vol. 22, pp. 506-517, 2001.

[15] N. A. Ibrahim, S. N. A. Ahmad, W. M. Z. W. Yunus, and K. Z. M. Dahlan, "Effect of electron beam irradiation and poly(vinyl pyrrolidone) addition on mechanical properties of polycaprolactone with empty fruit bunch fibre (OPEFB) composite," Polymer Letters, vol. 3, pp. 226-234, 2009.

[16] L. Liu, J. Yu, L. Cheng, and W. Qu, "Mechanical properties of poly (butylenes succinate) (PBS) biocomposites reinforced with surface modified jute fibre," Composites: Part A, vol. 40, pp. 669-674, 2009.

[17] M. J. John, B. Francis, K. T. Varughese, and S. Thomas, "Effect of chemical modification on properties of hybrid fiber biocomposites," Composites: Part A, vol. 39, pp. 352-363, 2008.

[18] M. Khalid, A. Salmiaton, C. T. Ratnam and C. A. Luqman, "Effect of trimethylolpropanetriacrylate (TMPTA) on the mechanical properties of palm fiber empty fruit bunch and cellulose fiber biocomposites," Journal of Engineering Science and Technology, vol. 3, no. 2, pp. 153-162, 2008.

[19] R. G. Liao, B. Yang, W. Yu and C. X. Zhoy, "Isothermal cold crystallization kinetics of polylactide/nucleating agents," Journal Applied Polymer Science, vol. 104, no. 1, pp. 310-317, 2007.

[20] M. F. Rosa, B.-S. Chiou, E. S. Medeiros, D. F. Wood, T. G. Williams, L. H. C. Mattoso, W. J. Orts, and S. H. Imam, "Effect of fiber treatments on tensile and thermal properties of starch/ethylene vinyl alcohol copolymers/coir biocomposites," Bioresource Technology, vol. 100, pp. 5196-5202, 2009.

[21] L. Y. Mwaikambo and M. P. Ansell, "Chemical modification of hemp, sisal, jute and kapok fibers by alkalization," Journal Applied Polymer Science, vol. 84, pp. 2222-2234, 2002.

[22] S. Singh, A. K. Mohanty, T. Sugie, Y. Takai, and H. Hamada, "Renewable resource based biocomposites from natural fiber and polyhydroxybutyrate-co-valerate (PHBV) bioplastic," Composites: Part A., vol. 39, pp. 875-886, 2008.

[23] P. Kamdem, H. C. Jiang, J. W. Freed, and M. L. Matuana, "Properties of wood plastic composites made of recycled HDPE and wood flour from CCA-treated wood removed from service," Composites: Part A, vol. 35, pp. 347-355, 2004. 